\title{
Actualización: Problemas en los pies de los pacientes con diabetes (segunda entrega): evaluación y manejo de las infecciones
}

\author{
Feet problems in diabetic patients (second part): evaluation and management of infections
}

Adriana Primerano*

\begin{abstract}
Resumen
La afección del pié en los pacientes con diabetes constituye por su importancia una entidad en si misma. En el espectro de su afectación encontraremos desde simples cambios en la sensibilidad y el trofismo de la piel, hasta úlceras de diferente magnitud, lesiones necróticas y osteomielitis, que pueden conducir a amputaciones y aún, comprometer la vida del paciente. En una entrega anterior desarrollamos aspectos generales del pié en las personas con diabetes y en particular, el abordaje de las ulceras no infectadas. En esta entrega se profundiza sobre el abordaje y manejo de las infecciones del pie, particularmente de las lesiones ulceradas y la osteomielitis.
\end{abstract}

\section{Abstract}

Foot involvement in diabetic patients is an entity by itself. The spectrum of Its affection range from skin changes in sensitivity and trofism to ulcers of different magnitude, necrotic lesions and osteomyelitis, which can lead to amputations and even compromise the patient's life .In a previous issue, general aspects of diabetic foot, and management of non-infected ulcers, in particular, were reviewed. In this issue we deepens on addressing the evaluation and management of diabetic foot infections, particularly of ulcerated lesions, and osteomyelitis.

Palabras clave: pie diabético, úlceras, diagnóstico, tratamiento. Key words: diabetic foot ulcers, diagnosis, treatment.

Primerano A. A. Problemas en los pies de los pacientes con diabetes (segunda entrega): evaluación y manejo de las infecciones. Evid. actual. práct. ambul; 11(4):115-119, Jul-Ago.2008.

\section{ÚLCERAS INFECTADAS}

\section{Aspectos generales y fisiopatología}

Las infecciones en los pies de los pacientes con diabetes suelen asentarse en úlceras previamente establecidas, siendo menos probable el camino inverso.

Si bien, la mayoría de las infecciones sólo compromete tejidos superficiales, en un $25 \%$ de los casos hay extensión a los planos profundos, pudiendo llegar a afectarse hueso. Aproximadamente la mitad de los diabéticos que han sufrido una infección del pie tendrán otra en los próximos años. La infección del pie en el paciente diabético es una complicación seria que aumenta el riesgo de amputación de la extremidad afectada: 10 a $30 \%$ de los pacientes diabéticos con una úlcera en el pie sufrirá una amputación, y se calcula que el $60 \%$ de las amputaciones son precedidas por una úlcera infectada.

El pie diabético, con pobre circulación, piel atrófica, disminución o pérdida de la sensibilidad protectora y alteración en los puntos de presión del pie, es extraordinariamente sensible a la infección. Además de las alteraciones ya mencionadas, existen otros factores que favorecen al desarrollo de infecciones en los pies: su especial anatomía que invita a la extensión de la infección, la presencia de microorganismos patógenos en sus pliegues del pie, las condiciones de humedad, y la proximidad con los zapatos y el suelo contaminado. Cabe destacar además, como factor de riesgo asociado, una tasa de colonización nasal por el Staphylococcus aureus más elevada que en la población no diabética'.

\section{Etiología}

En líneas generales, podría afirmarse que las úlceras agudas infectadas son de origen monomicrobiano y debidas a cocos Gram positivos. Por el contrario, las úlceras crónicas, tienden a ser de origen polimicrobiano.

Los agentes patógenos primarios, como el Staphylococcus aureus y Streotococcus pyogenes, son sin duda los más importantes y frecuentes. Sin embargo, otros agentes pueden ser responsables de la infección de las úlceras del pie diabético. Así por ejemplo, en las úlceras infectadas de pacientes hospitalizados y con infecciones graves pueden encontrarse de tres a cinco especies bacterianas distintas, pudiendo ser las mismas aeróbicas y anaeróbicas, en general bacilos gram negativos, especialmente Enterobacteriaceae.

De manera habitual, circunstancias como el tratamiento antibiótico previo, las infecciones cutáneas circundantes a la úlcera, o la exposición ambiental, modifican la flora colonizante habitual de las heridas y úlceras preexistentes. Pseudomona aeruginosa, se halla especialmente en las úlceras tratadas con apósitos húmedos o sometidas a hidroterapia'. En los pacientes previamente tratados con cefalosporinas es frecuente hallar Enterococcus sp. Las especies anaeróbicas estrictas, son casi siempre parte de infecciones mixtas en heridas con necrosis isquémica o que afectan tejidos profundos. Las especies multirresistentes predominan entre los pacientes tratados previamente con antibióticos, pacientes hospitalizados, o provenientes de áreas relacionadas con la asistencia sanitaria.

\section{Diagnóstico}

El diagnóstico de infección en una úlcera del pie de una persona con diabetes diabético debe basarse en la clínica. Para ello, la presencia de secreción purulenta o dos o más signos de inflamación como calor, rubor, induración o dolor; son indicadores de infección ${ }^{2}$. Este último síntoma puede estar ausente, ya que alrededor del $80 \%$ de los pacientes han perdido la sensibilidad dolorosa al momento del diagnóstico'. Las infecciones pueden asociarse a síntomas y signos de afección sistémica, como fiebre, escalofríos y leucocitosis; aunque con frecuencia éstos se encuentran ausentes. Ocasionalmente, úlceras sin signos inflamatorios pueden esconder una osteomielitis subyacente. El examen bacteriológico (directo y cultivo) del material tomado de una úlcera infectada -especialmente ante lesiones profundas-, constituye el método de elección para establecer el diagnóstico etiológico y guiar el tratamiento antibiótico ${ }^{3}$.

El rédito del estudio depende de la calidad de la muestra y del medio de transporte utilizado para enviarla al laboratorio de microbiología. Las muestras mas representativas suelen obtenerse por aspiración con jeringa de lesiones absedadas (mediante punción desde piel sana) o a través del raspado o biopsia de tejido del fondo de la úlcera, habiendo debridado previamente el tejido necrótico superficial.

Si previamente a la toma de la muestra, el paciente estuviera recibiendo tratamiento antibiótico, el mismo debería suspenderse 24 a 48 horas antes del procedimiento -de no ser posible se debería al menos esperar una vida media. Puede resultar útil además, la realización de un hisopado nasal para detectar portación de gérmenes como Staphilococcus, y eventualmente, hemocultivos de acuerdo al cuadro clínico.

Recientemente se han incorporando técnicas basadas en la detección y amplificación de ácidos nucleicos por medio de la 
reacción en cadena de la polimerasa (en inglés PCR). Las mismas han resultado de utilidad para identificar microorganismos de crecimiento lento o cultivo difícil, como Mycobacterium y Francisella, y también para buscar genes determinantes de resistencia bacteriana ${ }^{4}$

\section{Valoración clínica y tratamiento}

Si bien no existe un clasificación universalmente aceptada a la hora de establecer el grado de infección, la de la Sociedad Americana de Enfermedades Infecciosas es ampliamente aceptada por la comunidad médica. Ver tabla 1. La misma distingue entre infecciones leves, moderadas y severas. Las leves habi- tualmente no representan un riesgo para la extremidad y pueden ser manejadas en forma ambulatoria. En el otro extremo, las severas constituyen una amenaza para la extremidad y requieren internación, ya que es frecuente la coexistencia de osteomielitis. La presencia de celulitis extensa, abscesos profundos, fascitis necrosante y mionecrosis suelen asociarse a afección sistémica e inestabilidad metabólica, siendo casi siempre necesario realizar una cirugía de urgencia.

Existen diferentes esquemas terapéuticos antibacterianos empíricos. En general la elección debería ser individualizada frente a cada paciente, teniendo en cuenta la tinción de Gram y cuando corresponda, los cultivos. Ver tabla 1.

Tabla 1: clasificación y tratamiento de las ulceras infectadas del pie en pacientes con diabetes.

\begin{tabular}{|c|c|c|c|c|}
\hline Gravedad & Manifestaciones clínicas & $\begin{array}{c}\text { Esquema } \\
\text { emprico inicial }\end{array}$ & Esquema alternativo & Duración mínima \\
\hline Leve & $\begin{array}{l}\text { Presencia de pus o dos o más signos de inflamación } \\
\text { (eritema, dolor, calor o induración) más celulitis ó eritema } \\
\text { que se extiende a menos de } 2 \mathrm{~cm} \text { alrededor de la úlcera. } \\
\text { Las alteraciones se limitan a la piel y al tejido } \\
\text { subcutáneo superficial. }\end{array}$ & $\begin{array}{l}\text { Amoxicilina- } \\
\text { clavulanico }\end{array}$ & $\begin{array}{l}\text { Levofloxacina, moxifloxacina, clindamicina } \\
\text { ocotrimoxazol }\end{array}$ & $\begin{array}{l}\text { Una a dos semanas } \\
\text { por vía oral }\end{array}$ \\
\hline Moderada & $\begin{array}{l}\text { Igual al anterior, pero con celulitis ó eritema extendida a } \\
\text { más de } 2 \mathrm{~cm} \text { alrededor de la úlcera ó compromiso de } \\
\text { tejidos profundos (fascia, tendones, musculos, } \\
\text { articulaciones, hueso) ó gangrena ó abscesos. Aus encia de } \\
\text { toxicidad sistémica e inestabilidad metabólica. }\end{array}$ & \multicolumn{2}{|c|}{$\begin{array}{l}\text { Ertapenem +/- linezolid (IV o V0) ó Glucopéptido } \\
\text { Piperacilina-tazobactam ó Amoxicilina-clavulánico (IV o V0) } \\
\text { ó Cefalosporina de 3ra gen. ó Fluoroquinolona IV ó V0 más } \\
\text { metronidazol V0 o IV ó Clindamicina +/- linezolid VO o IV } \\
\text { ó glucopéptido }\end{array}$} & \multirow{2}{*}{$\begin{array}{l}\text { Salvo aclaración, por } \\
\text { vía intravenosa y } \\
\text { durante dos a } \\
\text { cuatro semanas, } \\
\text { ajustando los } \\
\text { esquemas de } \\
\text { acuerdo al resultado } \\
\text { de los cultivos }\end{array}$} \\
\hline Severa & $\begin{array}{l}\text { Signos de inestabilidad hemodinámica o metabólica } \\
\text { (fiebre, pirogenemia, taquicardia, hi potensión, confusión, } \\
\text { vómitos, leucocitosis, acidosis metabólica, hi perglucemia } \\
\text { marcada, uremia). }\end{array}$ & $\begin{array}{l}\text { Imipenem ó } \\
\text { Meropenem ó } \\
\text { Piperacilina- } \\
\text { tazobactam más } \\
\text { linezolido } \\
\text { glucopéptido }\end{array}$ & $\begin{array}{l}\text { Tigecilina }+/- \text { fluoroquinolona } a^{a} 0 \\
\text { amikacina }\end{array}$ & \\
\hline
\end{tabular}

VO: vía oral. IV: intravenosa. aCiprofloxacina o Levofloxacina. Modificado de: Lipsky AU, et al. Diagnosis and treatment of diabetic foot infections. Clin Infect Dis 2004 Oct 1;39(7):885-910. y Sociedad española de quimioterapia. Documento de consenso sobre el tratamiento antimicrobiano de las infecciones en el pie del diabético. Rev Esp Quimioterap 2007;20(1):77-92.

Tabla 2: dosis y forma de administración de la antibioticoterapia disponible para el tratamiento de las úlceras infectadas del pié en personas con diabetes.

\begin{tabular}{|c|c|c|c|c|}
\hline & \multicolumn{2}{|c|}{ Vía intravenosa } & \multicolumn{2}{|c|}{ Vía oral } \\
\hline Antibiótico & Dosis & Intervalo en horas & Dosis & Intervalo en horas \\
\hline Amoxicilina-clavulanico & $2 g$ y 0,2 & \multirow[t]{2}{*}{6 a 8} & 875 y $125 \mathrm{mg}$ & 8 a 12 \\
\hline Clindamicina & $600 \mathrm{mg}$ & & $300 \mathrm{mg}$ & 8 \\
\hline Cotrimoxazol & 160 y $800 \mathrm{mg}$ & \multirow[t]{2}{*}{8 a 12} & $160 / 800 \mathrm{mg}$ & 8 a 12 \\
\hline Ciprofloxacina & $400 \mathrm{mg}$ & & $500 \mathrm{mg}$ & \\
\hline Levofloxacina & $500 \mathrm{mg}$ & 12 a 24 & $500 \mathrm{mg}$ & 12 a 24 \\
\hline Ceftriaxona & $1 \mathrm{a} 2 \mathrm{~g}$ & 12 a 24 & & \\
\hline Vancomicina & 4 у $0,5 g$ & 6 a 8 & & \\
\hline Pi peracilina-Tazobactam & $500 \mathrm{mg}$ & 8 a 12 & & \\
\hline Metronidazol & $600 \mathrm{mg}$ & 12 & & \\
\hline Linezolid & 0,5 a $1 \mathrm{~g}$ & \multirow[t]{2}{*}{6 a 8} & & \\
\hline Imi penem & 0,5 a $1 \mathrm{~g}$ & & & \\
\hline Meropenem & $1 \mathrm{~g}$ & 24 & & \\
\hline Ertapenem & $50 \mathrm{mg}$ & 12 & & \\
\hline Tigeciclina & 400 a $600 \mathrm{mg}$ & \multirow[t]{2}{*}{24} & & \\
\hline Teicoplanina & 15 a $20 \mathrm{mg} / \mathrm{kg}$ & & & \\
\hline Amikacina & $2 g$ y 0,2 & 6 a 8 & & \\
\hline
\end{tabular}

Modificado de: Sociedad española de quimioterapia. Documento de consenso sobre el tratamiento antimicrobiano de las infecciones en el pie del diabéti$\mathrm{Co}^{4}$. Para información sobre la farmacocinética de estas drogas, referirse al documento original. 


\section{OSTEOMIELITIS}

\section{Aspectos generales, etiología y valoración clínica}

La infección ósea es una complicación frecuente de las úlceras del pie en pacientes con diabetes. Se estima que 50 a $60 \%$ de las infecciones moderadas a severas y 10 a $20 \%$ de las leves se complican con osteomielitis.

Generalmente la osteomielitis suele producirse por contigüidad y como resultado de la penetración en profundidad de una infección de los tejidos blandos. La infección ósea es polimicrobiana, siendo los agentes etiológicos mas frecuentes: Staphilococcus aureus (40\%), Staphilococcus epidermidis (25\%), Estreptococos (30\%) y Enterobacteriaceae (40\%). Citar

\section{Valoración clínica y diagnóstico}

El proceso tiende a ser crónico, de presentación insidiosa y de evolución tórpida. La localización más frecuente suele ser alrededor de la primera y la quinta articulación metatarsofalángica. Un tercio de los pacientes con infección avanzada muestran evidencia de artritis séptica en imágenes obtenidas por resonancia magnética ${ }^{5}$ y pueden ocurrir abscesos, frecuentemente localizados la zona delantera del pie $^{6}$.

\section{Test de contacto óseo}

Se debe sospechar compromiso óseo ante la presencia de úlceras grandes (lecho mayor a $2 \mathrm{~cm}$ ) profundas (más de $3 \mathrm{~mm}$ ) de larga evolución (mayor a cuatro semanas) o asociadas a eritrosedimentación mayor de $70 \mathrm{~mm} / \mathrm{hora}$.

Como parte del examen de la úlcera, puede resultar de utilidad el test de contacto óseo (en ingles, "Probe to bone test o PTB"). Este se realiza introduciendo un estilete en la úlcera, considerándose positiva a la prueba si se ve o si se toca hueso.

Clásicamente se le asigna alta especificidad (85\%) pero baja sensibilidad (66\%). En consecuencia, tiene valor para confirmar la presencia de osteomielitis pero nó para descartarla, especialmente cuando la prevalencia de osteomielitis es alta (ej. 66\%). Como es de suponer, cuando la prevalencia es más baja (12\% a $20 \%$ ) tiene menor valor predictivo positivo (VPP) pero mayor valor predictivo negativo (VPN). Por ejemplo, un estudio reciente ${ }^{7}$ realizado sobre una población con una prevalencia de osteomielitis de 12 a $20 \%$ informó alta sensibilidad (87\%; IC95\% 71 a 96) y especificidad (91\%; IC95\% 89 a 92) bajo VPP (57 a $62 \%$ ) y alto VPN (96 a 98\%) lo que ayudaría a excluir el diagnóstico en poblaciones representativas de la población general.

\section{Radiografía simple}

Los cambios típicos a buscar en la radiografía son resorción ósea, reacción perióstica y destrucción de la arquitectura ósea. Sin embargo, estos cambios óseos aparecen tardíamente -dos a cuatro semanas de iniciada la infección- pudiendo ser además indistinguibles de los cambios originados por la osteoartropatía neuropática de Charcot (diagnóstico diferencial). De este modo sólo tiene valor cuando sus resultados son anormales. Sin embargo, por su accesibilidad y bajo costo constituye el método complementario inicial a utilizar.

\section{Resonancia magnética por imágenes (RMI)}

Con esta metodología pueden ponerse en evidencia signos de osteomielitis como el edema de la medula ósea, lo que se traduce en disminución de la intensidad de la señal en T1, y en aumento de la misma en T2, especialmente si se utilizan técnicas de supresión de grasa. Puede prestarse a confusión el hecho de que el edema de causa no infecciosa también produce los mismos cambios, aunque suele ser de menor grado. De este modo, la probabilidad que el hallazgo se deba a una osteomielitis aumenta cuanto más pronunciados en intensidad son estos cambios y cuanto más próximos se hallen a una úlcera o foco inflamatorio del tejido blando. La RMI tiene la ventaja de que estos cambios aparecen más rápidamente que en la radiografía simple y permite una muy buena resolución espacial ${ }^{8}$. En la mayoría de los estudios comparativos, la RMI constituye la técnica por imagen mas confiable para el diagnostico de osteomielitis. Ver tabla 3.

\section{Gamagrafía ósea (GGO)}

Este método destaca áreas de mayor "captación" en zonas inflamatorias. Sin embargo, puede ser poco específica y resultar positiva (revelar focos hipercaptantes) en pacientes con procesos traumáticos o inflamatorios de origen no infeccioso. Su variante, la GGO con leucocitos marcados, logra mayor especificidad que la GGO convencional'. Así, ambas técnicas pueden resultar útiles a la hora de distinguir entre una osteomielitis y una afección artropática. Como limitación su costo efectividad disminuye cuando los focos infecciosos o inflamatorios están en los huesos planos -ricos en medula ósea-, dado que en estas regiones existe una intensa actividad leucocitaria fisiológica. Por el contrario, cuando existen áreas con destrucción ósea importante, pueden aparecer áreas no captantes que dificulten la identificaron de zonas con actividad infecciosa.

\section{Otros métodos de diagnóstico por imágenes}

La tomografía computada (TC) ha sido desplazada por la RMI. Sin embargo, tiene utilidad para determinar con mayor precisión la afectación del hueso cortical y localización de secuestros óseos en fases avanzadas ${ }^{1}$. La tomografía por emisión de positrones (PET, utilizando como marcador la 18-fluordesoxiglucosa) puede considerarse una alternativa a las exploraciones descritas, debido a la elevada fijación de la glucosa marcada en los focos infecciosos. Se han introducido equipos híbridos PETTC que combinan ambas técnicas de imagen. La mayor resolución espacial de la PET, respecto de los estudios gammagraficos convencionales, junto con la posibilidad de localizar con gran detalle los focos hipermetabólicos sobre la imagen de fusión con la TC, permite diferenciar con más precisión la afección de tejidos blandos frente a la infiltración ósea séptica. Por su elevado costo y su limitada experiencia en esta aplicación, este método no se considera de primera elección. Otra técnica que esta en fase de experimentación es la GGO con antibióticos marcados (por ej. ciprofloxacina) que promete una alta sensibilidad (cercana al $100 \%$ ) pero baja especificidad (37\%).

Tabla 3: sensibilidad y especificidad de los diferentes métodos disponibles para el diagnóstico de osteomielitis en pacientes diabéticos con infecciones en el pie.

\begin{tabular}{l|c|c}
\multicolumn{1}{c|}{ Estudio Complementario } & Sensibilidad & tspecificidad \\
\hline Radiografía simple & $61 \%$ & $72 \%$ \\
\hline Resonancia magnética & $96 \%$ & $87 \%$ \\
\hline Gamagrafía ósea (GGO) estándar & $85 \%$ & $36 \%$ \\
GG0 con leucocitos marcados con In111 & & \\
\hline
\end{tabular}

Modificado de Viadé J. Pie Diabético. Guía práctica para la prevención evaluación y tratamiento. Madrid, España. Editorial Médica Panamericana SA, 2006.

\section{Confirmación diagnóstica de la osteomielitis}

El diagnóstico definitivo de osteomielitis requiere la toma de una biopsia ósea para cultivo y examen histopatológico. Sin embargo antes de llegar a esta instancia suele ser necesario guiarse a través del uso de los métodos complementarios descriptos previamente. Ver figura 1. 
Figura 1: algoritmo diagnóstico ante sospecha de osteomielitis en lesiones del pié diabético.

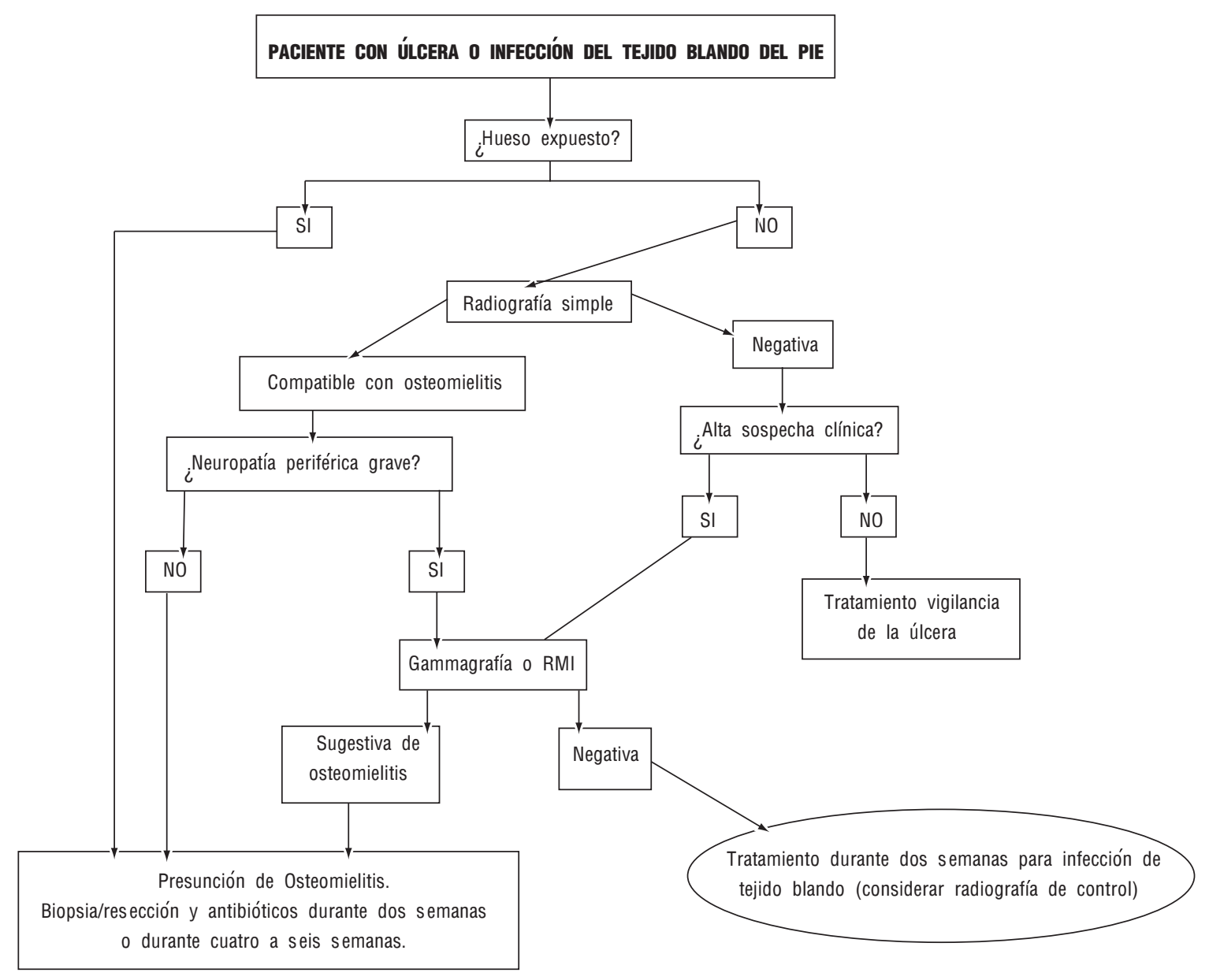

Modificado de: Lipsky A, et al.Diagnosis and treatment of diabetic foot infections. Clin Infect Dis 2004 Oct 1;39(7):885-910. RMI: resonancia magnética por imágenes.

Toma de la muestra

La biopsia ósea, con cultivo e histopatología del material obtenido, es el método de referencia para el diagnóstico de osteomielitis. Como en el caso de toma de material de úlceras, la muestra de hueso se debe obtener por cirugía o por biopsia percutánea, a través de tejido sano; ${ }^{9}$ ya que se consideran contaminadas las muestras obtenidas que se obtienen a través de la boca de la úlcera. Si el paciente recibió tratamiento antibiótico previo, el cultivo puede resultar negativo.

El estudio histopatológico de una osteomielitis mostrará infiltración por leucocitos y/u otras células inflamatorias y necrosis. $\mathrm{La}$ osteomielitis focal puede dar lugar a falsos negativos ${ }^{1}$. La sensibilidad del estudio es de $95 \%$ y la especificidad de $99 \%{ }^{1}$.

\section{Diagnóstico diferencial}

Ante un cuadro compatible con una úlcera infectada de pie diabético se deberán descartar otras causas de inflamación (fracturas, tromboflebitis, crisis gotosa, lipodermatoesclerosis, etc). Sin embargo el principal diagnóstico diferencial ante un pie deformado e inflamado es la neuroartropatía de Charcot. Esta fue descrita por primera vez por el neurólogo Jean Marie Charcot en 1868, pudiendo llegar su prevalencia al $15 \%$ de la población diabética si se tienen en cuenta las lesiones tempranas. Afecta a diabéticos tipo 1 y 2 con más de diez años de evolución y presencia de polineuropatía distal severa, habitualmente entre los 40 y los 60 años de edad. Generalmente afecta un pie, aunque en ocasiones puede ser bilateral. Se manifiesta en una o en varias articulaciones comprometiendo frecuentemente los huesos del tarso y mas excepcionalmente las falanges y los metatarsianos.

La explicación fisiopatológica más aceptada de esta entidad sostiene que la neuropatía autonómica (mediante apertura de shunts arteriovenosos y aumento consecuente del flujo sanguíneo) ocasiona osteopenia. El hueso osteopenico -frágil-, se ve a su vez afectado por múltiples agresiones mecánicas, y junto a la alteración de la sensibilidad dolorosa y propioceptiva (sensibilidad protectora) desencadenan un proceso de resorción ósea con pérdida de la estructura anatómica, seguida de un colapso articular y deformidad marcada. Los métodos radiológi- 
cos pueden resultar de ayuda para realizar el diagnóstico diferencial entre una etapa aguda del Charcot y una infección aguda. Ver tabla 4.

Tabla 4: diferencias radiológicas entre osteomielitis y neuroartropatia de Charcot.

\begin{tabular}{c|c|c} 
& Osteomielitis & Neuroartropatía de Charcot \\
\hline Lesión ós ea & Generalmente única & Múlti ple \\
\hline Compromiso cortical & Presente & Aus ente \\
\hline Límites de la lesión & No tiene límites & Se autolimita \\
\hline
\end{tabular}

\section{Tratamiento de la osteomielitis del pie en personas con diabetes}

Ante la falta de estudios clínicos prospectivos y aleatorizados, las recomendaciones actuales se basan principalmente en la opinión de expertos, persistiendo cierto grado de controversia. Los principios del tratamiento incluyen un drenaje adecuado, el debridamiento extenso del tejido necrótico, el tratamiento del espacio muerto, la cobertura con tejidos blandos adecuados y la restauración de la irrigación arterial; siendo necesaria a veces la amputación.

Si bien la enseñanza tradicional insiste en que es necesaria la resección del tejido óseo infectado, sus resultados no han sido muy satisfactorios. Por ejemplo, la amputación digital como único tratamiento, se ha asociado a una tasa de curación del $40 \%$. Por otro lado, la antibioticoterapia aislada también ostenta datos contradictorios: desde una tasa de curación cercana a las dos terceras partes de los casos hasta afirmar otras series, peores resultados y mayores tasas de amputación ${ }^{4}$.

La Asociación Americana de Diabetes recomienda que se reseque todo o la mayor parte del hueso infectado, si no va en desmedro de la funcionalidad del pie. En los casos de osteomielitis extensa de las falanges o el metatarsiano, aconseja la amputación lo mas distal posible, con posibilidad de curar y devolver al paciente una función del pie lo más cercana a la original. En todos los casos aconseja asociar tratamiento antibiótico durante dos semanas si se extirpó todo el hueso infectado, y al menos durante cuatro semanas si se adopto una actitud más conservadora ${ }^{4}$.

La osteomielitis focal puede tratarse con antibioticoterapia prolongada, recomendándose al inicio del tratamiento la adminis- tración endovenosa, pasandose luego a la vía oral. La duración será de al menos dos meses, pero habitualmente son necesarios entre tres y seis.

Al inicio el tratamiento será empírico y luego se ajustara sobre la base de los resultados del cultivo de las muestras de hueso obtenidas al momento del desbridamiento o la biopsia.

Los mejores resultados ( $80 \%$ de respuesta) se obtienen con la combinación de debridamiento de la cortical ósea y la cobertura con tejidos blandos, seguidos de antibioticoterapia prolongada y dirigida según los resultados del cultivo.

\section{Valoración del riesgo de amputación}

Los factores predictores de amputación mejor identificados son la neuropatía periférica, la ulceración, la infección y la enfermedad arterial oclusiva. De todos ellos, el precursor más común es la ulceración, ya que cerca del $85 \%$ de las amputaciones están precedidas por una úlcera. Según su extensión y la presencia o no de isquemia o infección -ver Clasificación de Texas, en la entrega anterior de EVIDENCIA ${ }^{9}$-, un estudio mostró que del total de pacientes diabéticos que acudieron al hospital para ser evaluados, $28,6 \%$ sufrieron algún tipo de amputación. Los pacientes cuya úlcera había afectado el hueso (grado 3) tuvieron una probabilidad 11 veces mayor de acabar con una amputación del antepié o de un nivel superior (infracondilea o supracondilea). En los pacientes con úlcera en estadio $D$ (con infección o isquemia) esta probabilidad fue 90 veces superior ${ }^{10}$.

\section{Conclusión}

El tratamiento de las infecciones del pie en pacientes con diabetes es compleja por los diversos factores que intervienen en su desarrollo. Las decisiones terapéuticas se basan generalmente en opinión de expertos, ya que hasta al momento no se cuenta con evidencia clínica suficiente como para estandarizar el tratamiento. Esto es debido a la falta de homogeneidad de los ensayos clínicos realizados hasta el momento.

El "pie diabético infectado" es sin lugar a dudas una entidad prevenible, siendo crucial en su evolución realizar un diagnóstico precoz. Con el objetivo de disminuir su prevalencia y mejorar la calidad de vida de nuestros pacientes, la educación diabetológica y la atención multidisciplinaria deberán constituirse en los pilares básicos de la prevención y el abordaje de estas entidades clínicas.

\section{Referencias}

1. Viadé J. Pie Diabético. Guía práctica para la prevención evaluación y tratamiento. Madrid, España. Editorial Médica Panamericana SA, 2006.

2. Lipsky A, et al.Diagnosis and treatment of diabetic foot infections. Clin Infect Dis 2004 Oct 1;39(7):885-910.

3. Ertugrul $\mathrm{M}$, et al. The diagnosis of osteomyelitis of the foot in diabetes: microbiological examination vs. magnetic resonance imaging and labelled leucocyte scanning. Diabet Med 2006;23(6):649-53.

4. Sociedad española de quimioterapia. Documento de consenso sobre el tratamiento antimicrobiano de las infecciones en el pie del diabético. Rev Esp Quimioterap 2007;20(1):77-92. Disponible en: http://www.seq.es/seq/0214-3429/20/1/consenso1.pdf (último acceso 08/08/2008).

5. Ledermann H, et al. MR Image Analysis of Pedal Osteomyelitis: distribution, Patterns of spread, and Frequency of Associated Ulceration and septic Arthritis. Radiology 2002;223:747-755.

6. Ledermann H, et al. Pedal Abscesses in Patients Suspected of Having Pedal Osteomyelitis: Analysis with MR Imaging. Radiology 2002;224:649-655.

7. Lavery LA, Armstrong DG, Peters EJ et al. Probe-to-bone test for diagnosing diabetic foot osteomyelitis. Diabetes Care 30(2):270 -274, 2007.

8. Kapoor A, et al. Magnetic resonance imaging for diagnosing foot osteomyelitis: a meta-analysis. Arch Intern Med 2007;167(2):125-132.

9. Primerano A. Problemas en los pies de los pacientes con diabetes: generalidades y manejo de las úlceras. Evid. actual. práct. ambul; 11(3):83-86, May-Jun.2008. Disponible en URL: http://www.foroaps.org/hitalba-paginaarticulo.php?cod_producto=2297\&vol=11\&nr_bi=3\&ano=2008 (último acceso 14/08/08).

10. Senneville $\mathrm{E}$, et al. Culture of percutaneous bone biopsy specimens for diagnosis of diabetic foot osteomyelitis: concordance with ulcer swab cultures. Clin infect Dis 2006; $42(1): 57-62$. 